\title{
Editorial: Eco-Evolutionary Dynamics of Marine Biodiversity in Human-Dominated Coastalscapes
}

\author{
Juan F. Blanco-Libreros ${ }^{1,2 *}$, José M. Riascos ${ }^{2,3 *}$, Benjamin Branoff ${ }^{4}$ and Eliza C. Heery ${ }^{5,6}$ \\ ${ }^{1}$ Instituto de Biología, Universidad de Antioquia - Ciudad Universitaria, Medellín, Colombia, ${ }^{2}$ Corporation Center of \\ Excellence in Marine Sciences, Bogotá, Colombia, ${ }^{3}$ Corporación Académica Ambiental, Universidad de Antioquia - Sede \\ Ciencias del Mar, Turbo, Colombia, ${ }^{4}$ Institute of Plant Sciences and Microbiology, Universität Hamburg, Hamburg, Germany, \\ ${ }^{5}$ Friday Harbor Laboratories, University of Washington, Friday Harbor, WA, United States, ${ }^{6}$ Tennenbaum Marine \\ Observatories Network and Smithsonian Environmental Research Center, Smithsonian Institution, Edgewater, MD, \\ United States
}

Keywords: eco-evolutionary dynamics, human domination, marine ecosystems, coastalscapes, cities, urbanization

\section{Editorial on the Research Topic}

\section{Eco-Evolutionary Dynamics of Marine Biodiversity in Human-Dominated Coastalscapes}

\section{OPEN ACCESS}

Edited and reviewed by: Jorge L. Gutiérrez,

Consejo Nacional de Investigaciones

Cientificas y Técnicas

(CONICET), Argentina

*Correspondence:

Juan F. Blanco-Libreros juan.blanco@udea.edu.co José M. Riascos

jose.riascos@udea.edu.co

Specialty section:

This article was submitted to Global Change and the Future Ocean,

a section of the journal

Frontiers in Marine Science

Received: 09 November 2021 Accepted: 03 December 2021 Published: 21 December 2021

Citation:

Blanco-Libreros JF, Riascos JM,

Branoff B and Heery EC (2021)

Editorial: Eco-Evolutionary Dynamics of Marine Biodiversity in

Human-Dominated Coastalscapes.

Front. Mar. Sci. 8:812202.

doi: 10.3389/fmars.2021.812202
Humans have substantially altered marine and coastal environments globally, particularly through the processes of urbanization and urban development (Lazarus, 2017). Urbanized marine environments are now widespread and expanding rapidly, yet we know little about the intertidal and subtidal ecology of these communities (Dafforn et al., 2015; Todd et al., 2019). Determining how marine life persists and how it assimilates and adapts to urban stressors is critical if we are to build a comprehensive understanding and conceptual framework for managing coastal systems of the future. This all starts by evaluating and characterizing the variation in ecological functioning, life history traits, and eco-evolutionary processes of biota across existing humandominated coastalscapes. While there is a large amount of empirical evidence on terrestrial plant and animal responses to urbanization worldwide (e.g., Alberti et al., 2017), there is less information about marine systems (see Todd et al., 2019 for a recent synthesis).

Greater effort is needed to describe eco-evolutionary dynamics in human-dominated marine and coastal environments, particularly at water-land-air transitions, or "coastalscapes," where human impacts are most likely to impose selective pressure. We define coastalscapes (building upon the seascape definition sensu Pittman et al., 2021) as the transitional zone extending from the shallow subtidal to upland watersheds in close proximity to shore $(<10 \mathrm{~km})$. This includes a complex mosaic of terrestrial, intertidal, and submerged spatial units, exhibiting both a $2 \mathrm{D}$ or $3 \mathrm{D}$ configuration. Coastalscapes are dynamic over various time scales ranging from hours to years or decades. Human-dominated coastalscapes exhibit altered physicochemical conditions (e.g., shifted hydrological regimes, increased land-derived nutrients and pollutants, increased light and noise), spatial configuration (e.g., armouring structures, engineered shorelines, and fragmented intertidal habitats), and temporal variability (e.g., due to human activities like dredging and fishing, as well as human modifications that increase disturbance frequency like shoreline hardening). Human pressures may originate from the terrestrial, intertidal or subtidal realm within a coastalscape and propagate through to surrounding environments.

The collection of articles presented here encompasses two topical areas: (i) life history, behavioral, and functional traits of mobile fauna across human-dominated coastalscapes, and (ii) mangroves as part of tropical coastalscapes where eco-evolutionary dynamics are influenced by human activities, particularly urbanization. 
Three articles dealt with traits of marine fishes and other megafauna in human-dominated coastalscapes. Cernadas-Martín et al. studied spatio-temporal variability in the diet of summer flounder (Paralichthys dentatus) across 13 shallow-water station areas in Shinnecock Bay (Long Island, USA). Summer flounder is a recreationally and commercially important flatfish species that recently achieved recovery status following a stock collapse in 1989. However, it migrates between human-dominated estuarine and off-shore waters and in areas subject to hazardous algal blooms triggered by upland-urban development. The study found fish diets were strongly influenced by water quality and benthic habitat; the most salient ecological pattern was a shift from fishto invertebrate-dominated diets between pristine and more degraded seagrass habitats. In another North American coastalscape (Plum Island Estuary, MA, USA), Taylor et al. studied the grouping behavior and movement of the striped bass (Morone saxatilis) relative to the physical environment. By tagging and tracking 59 individuals across a network of 26 telemetry stations, they found multiple coexisting groups, described group characteristics, and unraveled associations between groups, physical site type, and region. Finally, Smallegange et al. investigated variation in the functional traits of charismatic marine megafauna (i.e., mobulid rays, cheloniid sea turtles, and carcharhinid sharks) across human-dominated coastalscapes. Their findings suggested that while fast-paced life histories are more responsive to favorable environmental conditions, slow-paced life histories are the winners under environmental degradation, presumably reflecting a trade-off between reproduction and survival.

Mangroves are highly diverse intertidal habitats that can persist in some human-dominated coastalscapes and serve as a "fascinating evolutionary laboratory" (Dahdouh-Guebas et al.). Four papers in the collection explored urban-related spatial patterns in mangroves and their associated fauna. Ramos et al. found that the mangrove-tree climbing periwinkle (Littoraria angulifera) colonized anthropogenic substrates (boulder seawalls and built structures) on the periphery of a small city in the Urabá Gulf (Colombia, Southern Caribbean) where mangrove forests have been cleared. Their surveys of periwinkles across 13 locations in the large gulf also found reduced mean shell size and a preference for wave-protected microhabitats in urban settings. The authors propose that thermal regimes in the human-made, wave-exposed substrates may exert selective pressure on individual morphology and behavior. Branoff and Campos-Cerqueira used passive acoustic monitoring of avian-anuran assemblages in Puerto Rico (Greater Antilles) and urbanization gradients at two different spatial scales (island-wide and local) to assess whether mangrove-specialist species utilize urban space and to test the hypothesis that urban communities are dominated by generalists. Island-wide, urban areas were similar in anuran and bird species composition relative to more rural areas, and there was no observed difference in richness. Locally, avian richness decreased as urbanization decreased. Mangrove canopy height was a strong predictor of avian richness at multiple scales. Blanco-Libreros and Ramírez-Ruiz assessed the linkages between urbanization and habitat features of vulnerable neotropical true-mangrove tree species (Pelliciera spp.). Across the distributional range in northern South America, the authors found that mangrove habitat fragmentation (meaning lower core area and cohesion among patches) was positively correlated with urbanization, and suggest this pattern may correspond with ecological and evolutionary changes in small, genetically isolated populations of these species. Triest et al. characterized the genetic structure of three species of the mangrove genus Avicennia across human-dominated coastalscapes in The Philippines. Although genetic structure was not strongly related to human-induced variation in Avicennia patch size, their findings highlight proximity to open water and narrowness of mangrove forests as important factors influencing diversity, inbreeding, and fine-scale spatial genetic structure.

Altogether, these papers underscore the importance of anthropogenic and urban-related stressors on ecological patterns and evolutionary processes within coastalscapes. They also highlight the need for expanded research on urban eco-evolutionary dynamics in the marine realm similar to that proposed by Rivkin et al. (2018). In particular, studies that improve understanding of rapid speciation and the genetic basis for distinguishing adaptive from non-adaptive phenotypic change will be important contributions. As this body of work expands, we suggest that marine eco-evolutionary dynamics should be taken into account in urban planning, conservation practice, pest management, and public engagement (as argued by Rivkin et al., 2018). In the interim, we also encourage the use of human-dominated coastalscapes not only as laboratories and model systems but as opportunities for connecting people with marine ecosystems through citizen science. A multifaceted research agenda that integrates both social and ecological interests in non-traditional ways would catalyse understanding of the bi-directional relationships between ecology and evolution in human-dominated coastalscapes, providing greater insight into core areas for conservation on urbanized coasts (see Dearborn and Kark, 2009).

\section{AUTHOR CONTRIBUTIONS}

All authors listed have made a substantial, direct, and intellectual contribution to the work and approved it for publication.

\section{ACKNOWLEDGMENTS}

We thank all the contributors to this Research Topic. 


\section{REFERENCES}

Alberti, M., Correa, C., Marzluff, J. M., Hendry, A. P., Palkovacs, E. P., Gotanda, K. M., et al. (2017). Global urban signatures of phenotypic change in animal and plant populations. Proc. Natl. Acad. Sci. U.S.A. 114, 8951-8956. doi: 10.1073/pnas.1606034114

Dafforn, K. A., Glasby, T. M., Airoldi, L., Rivero, N. K., Mayer-Pinto, M., and Johnston, E. L. (2015). Marine urbanization: an ecological framework for designing multifunctional artificial structures. Front. Ecol. Environ. 13, 82-90. doi: 10.1890/140050

Dearborn, D. C., and Kark, S. (2009). Motivations for conserving urban biodiversity. Conserv. Biol. 24, 432-440. doi: 10.1111/j.1523-1739.2009. 01328.x

Lazarus, E. D. (2017). Toward a global classification of coastal anthromes. Land 6, 13. doi: $10.3390 /$ land6010013

Pittman, S. J., Yates, K. L., Bouchet, P. J., Álvarez-Berastegui, D., et al. (2021). Seascape ecology: identifying research priorities for an emerging ocean sustainability science. Mar. Ecol. Prog. Ser. 663, 1-29. doi: 10.3354/meps1 3661

Rivkin, L. U., Santangelo, J. S., Alberti, M., Aronson, M. F. J., de Keyzer, C. W., Diamond, S. E., et al. (2018). A road map for urban evolutionary ecology. Evol. Appl. 12, 384-398. doi: 10.1111/eva.1 2734
Todd, P. A., Heery, E. C., Loke, L. H., Thurstan, R. H., Kotze, D. J., and Swan, C. (2019). Towards an urban marine ecology: characterizing the drivers, patterns and processes of marine ecosystems in coastal cities. Oikos 128, 1215-1242. doi: 10.1111/oik.05946

Conflict of Interest: The authors declare that the research was conducted in the absence of any commercial or financial relationships that could be construed as a potential conflict of interest.

Publisher's Note: All claims expressed in this article are solely those of the authors and do not necessarily represent those of their affiliated organizations, or those of the publisher, the editors and the reviewers. Any product that may be evaluated in this article, or claim that may be made by its manufacturer, is not guaranteed or endorsed by the publisher.

Copyright (๑) 2021 Blanco-Libreros, Riascos, Branoff and Heery. This is an openaccess article distributed under the terms of the Creative Commons Attribution License (CC BY). The use, distribution or reproduction in other forums is permitted, provided the original author(s) and the copyright owner(s) are credited and that the original publication in this journal is cited, in accordance with accepted academic practice. No use, distribution or reproduction is permitted which does not comply with these terms. 